University of Nebraska - Lincoln

DigitalCommons@University of Nebraska - Lincoln

2019

Employee performance, well-being, and differential effects of human resource management subdimensions: Mutual gains or conflicting outcomes?

Chidiebere Ogbonnaya

Jake G. Messersmith

Follow this and additional works at: https://digitalcommons.unl.edu/managementfacpub

Part of the Business Administration, Management, and Operations Commons, Management Sciences and Quantitative Methods Commons, Performance Management Commons, and the Strategic Management Policy Commons

This Article is brought to you for free and open access by the Management Department at DigitalCommons@University of Nebraska - Lincoln. It has been accepted for inclusion in Management Department Faculty Publications by an authorized administrator of DigitalCommons@University of Nebraska - Lincoln. 


\title{
Employee performance, well-being, and differential effects of human resource management subdimensions: Mutual gains or conflicting outcomes?
}

\author{
Chidiebere Ogbonnaya ${ }^{1} \&$ Jake Messersmith ${ }^{2}$ \\ 1 Norwich Business School, University of East Anglia, Norwich, UK \\ 2 College of Business, University of Nebraska-Lincoln, Lincoln, Nebraska, USA \\ Correspondence - Chidiebere Ogbonnaya, Norwich Business School, University of East Anglia, \\ Norwich Research Park, Norwich, UK. Email: c.ogbonnaya@uea.ac.uk \\ ORCID Chidiebere Ogbonnaya http://orcid.org/0000-0002-0704-5717
}

\begin{abstract}
The human resource management (HRM) literature supports the idea that coherent systems of HRM practices can induce attitudinal effects when perceived subjectively by employees. Recently, scholars have proposed that subdimensions of HRM systems exist and account for variance in outcomes. This study explores differential effects of three subdimensions of HRM systems (skill-, motivation-, and opportunity-enhancing HRM practices) on employee innovative behaviors and well-being. Our predictions are based on the mutual gains perspective, which specifies positive relationships between HRM practices and employee performance, and the conflicting outcomes perspective that links HRM practices to higher job demands and stress. Using data from the Finnish 2012 Practices of Working Life Survey, we find support for both the mutual gains and conflicting outcomes perspectives; however, we also show that the effects of the subsets of HRM practices are heterogeneous.
\end{abstract}

Keywords: affective commitment, HRM practices, innovative behaviors, job demands, stress, well-being

Published in Human Resource Management Journal 29 (2019), pp 509-526.

doi:10.1111/1748-8583.12203

Copyright (C) 2018 John Wiley \& Sons Ltd. Used by permission.

Submitted 27 February 2017; revised 15 June 2018; accepted 19 June 2018. 


\section{Introduction}

Although an extensive body of research has documented the benefits of coherent systems of human resource management (HRM) practices (Jiang, Lepak, \& Baer, 2012; Van De Voorde, Paauwe, \& Van Veldhoven, 2012), critical questions remain regarding the actual influence of such systems on employee performance and well-being. From a mutual gains perspective, HRM systems-including staff training, selective hiring, performance appraisal, workplace support, team working, and job autonomy-promote performance benefits by aligning employees' interests more closely with organizational goals (Guest, 2017; Van de Voorde et al., 2012). HRM systems create a "win-win" situation given that employee well-being is enhanced and performance is strengthened. By contrast, others argue that any performance benefits of HRM systems are offset by increased job demands, stress, and work intensification (Kroon, Van de Voorde, \& Van Veldhoven, 2009; Ramsay, Scholarios, \& Harley, 2000). HRM systems optimize employees' skills and performance, but with little or no benefit to their well-being (Ogbonnaya, Daniels, Connolly, \& Van Veldhoven, 2017). These competing views remain at the heart of HRM research and highlight the possibility of trade-offs between the performance and well-being benefits of HRM systems.

One approach to understanding these trade-offs is to consider the idiosyncratic experiences of employees. There is evidence that individual employees' actual perceptions of HRM systems rather than managers' reports of the intended outcomes or existence of such systems are relevant for understanding the effects of HRM systems on employee attitudes and behaviors (Alfes, Shantz, Truss, \& Soane, 2013; Jiang, Hu, Liu, \& Lepak, 2017; Van De Voorde \& Beijer, 2015). This research stream suggests that the attitudinal or behavioral benefits of HRM systems are realized if employees hold positive perceptions as to why such systems are being implemented (Nishii, Lepak, \& Schneider, 2008). Individual employees might experience the same set of HRM practices disparately and consequently react in a heterogeneous manner (Alfes et al., 2013; Van De Voorde \& Beijer, 2015). Building upon these arguments, the present study explores the potential role of perceived HRM practices in understanding the trade-offs between employee performance and well-being. The term trade-offs highlights the importance of perceived HRM systems in ensuring adequate levels of employee performance while also minimizing any potential adverse consequences for their well-being. 
Our main contribution lies in examining the differential performance and well-being consequences of three subdimensions of HRM systems. There is growing research interest in understanding how different combinations of HRM practices influence workplace outcomes (see Gardner, Wright, \& Moynihan, 2011; Gong, Law, Chang, \& Xin, 2009; Jiang et al., 2012; Subramony, 2009). In a recent meta-analytic study, Jiang et al. (2012) reported differential effects of three dimensions of HRM systems (skill-, motivation-, and opportunity-enhancing HRM practices) on human capital and employee motivation, as well as operational and financial outcomes. However, Jiang et al. and others (e.g., Subramony, 2009) approach this subject from an organizational standpoint, leaving gaps in our knowledge of how subsets of HRM practices might operate from the perspective of employees. In the present study, we focus on the relationships between subsets of HRM systems and employees' self-reports of innovative behaviors and perceptions of stress-relationships that have yet to be explored in this literature.

The present article builds on the work of Jiang et al. (2012) and others in creating a more nuanced understanding of skill-, motivation-, and opportunity-enhancing subdimensions of HRM practices and employee outcomes. In line with the mutual gains perspective (Van de Voorde et al., 2012), we examine the extent to which each of these HRM dimensions might influence employees' performance (measured by their innovative behaviors) through affective commitment. On the basis of the conflicting outcomes perspective (Kroon et al., 2009), we examine which HRM dimensions induce high job demands and, consequently, higher levels of stress. Our study has important implications for debates as to whether organizations should adopt entire systems of HRM practices or focus on a core set of practices that provide tangible benefits for both employee performance and well-being (Boxall, Ang, \& Bartram, 2011). Our approach aims to address an important limitation in previous studies that presumes HRM practices are experienced uniformly by employees.

\section{Theoretical background and hypotheses}

A dominant theme in HRM research is the notion that individual HRM practices are intercorrelated and should therefore be examined in bundles, rather than in isolation, to encourage desirable outcomes (Appelbaum, Bailey, Berg, \& Kalleberg, 2000; Macky \& Boxall, 2007). Individual 
HRM practices are mutually supportive of each other and induce complementary effects when used together in a coherent manner. This approach is based on the idea of "internal fit" among HRM practices, which means that each practice will enhance and support the effectiveness of another (Delery, 1998). Unless HRM practices are "bundled" or used together in coherent systems, their actual relevance and impact on outcomes may be underutilized. Researchers have further suggested that employees' actual perceptions of HRM systems are more proximal to employees' workplace behaviors and therefore better determinants of their performance (Alfes, Shantz, \& Truss, 2012; Alfes et al., 2013; Jiang et al., 2017). When HRM practices are used together in a consistent manner, they afford employees an opportunity to make subjective attributions about their work environment, leading to outcomes that are typically attitudinal in nature (Van De Voorde \& Beijer, 2015). Thus, to examine employee-level outcomes of HRM systems, it is sensible to focus on employees' perceptions of such systems (Alfes et al., 2013).

There is substantial evidence that HRM systems promote different measures of organizational performance (see reviews: Jiang et al., 2012; Van de Voorde et al., 2012). However, when it comes to employees' perceptions and reactions to HRM systems, a less succinct picture begins to emerge, raising questions as to whether HRM systems are indeed beneficial for employees. The body of research on employees' experiences of HRM systems is structured around two theoretical viewpoints: the mutual gains and conflicting outcomes perspectives.

\subsection{Mutual gains perspective}

The mutual gains perspective stipulates shared benefits for both the organization and employees (Van de Voorde et al., 2012). The key assumption is that HRM systems create a win-win situation in which positive employee attitudes are critical for achieving performance improvements (Appelbaum et al., 2000). As a managerial strategy that applies throughout the workplace, HRM systems provide the necessary operational control for employees to maximize their skills and perform their jobs in ways that are consistent with organizational goals (Guest, 2017; Takeuchi, Chen, \& Lepak, 2009). This perspective argues that employees experience improved job quality and feel a stronger sense of attachment towards the organization, all leading to performance benefits. Recently, scholars have proposed the view that organizational outcomes 
may be too distal for assessing the impact of HRM systems (Alfes et al., 2013; Ogbonnaya et al., 2017; Takeuchi et al., 2009). As a result, proponents of the mutual gains paradigm are paying more attention to the mediating role of employee outcomes in relation to HRM systems and organizational performance. Within this realm, employees' workplace attitudes and behaviors are seen as important mechanisms for explaining the performance benefits of HRM systems.

The present study examines the affective commitment of employees as an important channel through which perceived HRM practices might influence employee performance. Affective commitment is defined as an individual's strong emotional attachment towards the organization (Allen \& Meyer, 1990). It relates to employees' sense of organizational allegiance and willingness to exercise discretionary effort (Paré \& Tremblay, 2007). The present study focuses on one such discretionary behavior: employees' innovative behaviors. Innovative behaviors cover a broad set of actions including the capacity to develop new ideas, take the necessary steps to implement such ideas, and seek creative ways to improve the ideas (De Jong \& Den Hartog, 2010; Ma Prieto \& Pilar Perez-Santana, 2014). It represents an important distal behavioral measure likely to be influenced by the HRM system (Hayton, 2005). Therefore, we examine employees' innovative behaviors as mediated by affective commitment.

Previous studies have reported significant links between HRM systems and employee commitment (e.g., Gong et al., 2009; Gould-Williams, 2003; Ogbonnaya et al., 2017; Paré \& Tremblay, 2007). Paré and Tremblay's (2007) study of 394 Canadian workers, for example, showed HRM practices are positively related to both the affective and continuance dimensions of commitment. Similarly, Gong et al.'s (2009) study of Chinese firms showed evidence that workers' level of commitment is enhanced as HRM practices are perceived to be valuable for their job performance. Drawing on social exchange theory, these studies and others (e.g., GouldWilliams, 2003; Ogbonnaya et al., 2017) describe the mediating role of employee commitment in terms of the HRM-performance relationship. When employers invest in HRM practices, they send signals that indicate employees represent a major source of competitive advantage for the organization. In turn, employees perceive these signals as favorable treatment from the employer and reciprocate through a greater sense of organizational attachment. With increased organizational attachment, employees are more likely to exert themselves on behalf of 
the organization. They could, for example, exercise novelty towards developing new products and services (Ma Prieto \& Pilar Perez-Santana, 2014) or apply their creative knowledge towards improving organizational effectiveness (Hayton, 2005). On the basis of the foregoing, we test the mutual gains perspective as follows.

Hypothesis 1. HRM systems increase employees' affective commitment, which in turn improves the innovative behaviors of employees.

\subsection{Conflicting outcomes perspective}

Unlike the mutual gains perspective, the conflicting outcomes (or critical) perspective portrays HRM systems as a strategy for imposing greater work demands on employees, with little or no benefit to their well-being (Macky \& Boxall, 2008; Ogbonnaya et al., 2017; Ramsay et al., 2000). The logic behind this perspective is that harsh economic conditions and labor market competition place undue pressures on employers to follow an intensification approach towards improving organizational performance (Ogbonnaya et al., 2017). Under greater external pressures, employers adopt HRM systems as a means to enhance employee effort and elicit greater value from human capital resources, with little emphasis placed on employee well-being (Ramsay et al., 2000). The critical perspective owes its roots to the "labor process" paradigm in which employers, in an effort to drive organizational performance, engage employees through heightened work demands and longer working hours, without providing adequate levels of support (Ramsay et al., 2000). Within such systems, employees feel pressured to work too hard and undertake too many job tasks, leading to greater perceptions of stressful work.

Although the conflicting outcomes perspective has received less scholarly attention than the mutual gains perspective, existing research tends to focus on employees' experience of stress-related outcomes (e.g., Boxall \& Macky, 2014; Kroon et al., 2009; Macky \& Boxall, 2008; Ogbonnaya $\&$ Valizade, 2015). Work-related stress is an employee well-being outcome characterized by the tendency to feel tense, exhausted, restless, or anxious in the context of work. Under the conflicting outcomes perspective, job demands are seen as the main mediating mechanism for explaining the stress-related effects of HRM systems (e.g., Kroon et al., 2009; Macky \& Boxall, 2008). Job demands are defined as the amount of 
work effort expended in relation to the amount of hours invested in undertaking one's job (Macky \& Boxall, 2008). Kroon et al.'s (2009) study of 393 employees nested within 86 organizations found evidence that HRM practices influence workers' experience of emotional exhaustion through heightened work demands. Kroon et al. argued that HRM systems stimulate stress-related outcomes because they are designed to elicit greater work effort from employees. Similarly, Ogbonnaya et al.'s (2017) comparative study of British workers found evidence that HRM practices are associated with higher levels of work intensity, which in turn induces stressful work patterns. In line with these studies, we test the conflicting outcomes perspective, as follows.

Hypothesis 2. HRM systems increase employees' reports of job demands, which in turn increase employees' experience of stress.

\subsection{Subsets of HRM systems}

Although the logic of combining individual HRM practices into coherent systems has gained prominence among HRM scholars, some of its key assumptions have been challenged. It is argued, for example, that the existence of multiple management goals (e.g., cost reduction vs. human capital development) may cause discrepancies that undermine the level of interconnectedness among components of HRM systems (Macky \& Boxall, 2007). Such discrepancies may create strategic tensions that invalidate the notion of internal coherence and prompt individual components of HRM systems to pull in different and conflicting directions (Boxall et al., 2011; Ogbonnaya et al., 2017). In other words, different configurations of HRM practices may not necessarily have equivalent effects as prescribed by the systems approach to HRM (Gardner et al., 2011; Gong et al., 2009; Jiang et al., 2012; Subramony, 2009). With these arguments taken into account, the main issues addressed in the remaining sections of the present study relate to subsets of HRM systems.

One influential theory for identifying subsets or subdimensions of HRM systems is the ability-motivation-opportunity (AMO) model (Appelbaum et al., 2000; Macky \& Boxall, 2007). The AMO model stipulates three key components of HRM systems: ability (or skill) HRM practices such as selective hiring and training develop employees' skills for adequate levels of performance; motivation HRM practices (e.g., 
performance appraisals and workplace support) provide inducements for employees to utilize their skills and exercise discretionary effort; $o p$ portunity HRM practices such as team working and job autonomy create conditions for employees to engage actively at work. Drawing on these fundamental ideas, some studies (e.g., Jiang et al., 2012; Subramony, 2009) have shown evidence that these three subdimensions of HRM systems influence organizational outcomes differently. We take our lead from these studies to identify three subdimensions of the HRM system and examine their respective roles in explaining the trade-offs between employee performance and well-being.

Consistent with the mutual gains perspective, we expect all three subdimensions to have positive relationships with the affective commitment of employees. Perceived HRM practices improve employee commitment through establishing positive social exchange relationships between management and employees (Gong et al., 2009; Gould-Williams, 2003). Such practices operate as consistent channels by which information about what the organization expects of employees and what employees can expect in return, are communicated (Ogbonnaya et al., 2017). For example, skill-enhancing HRM practices such as selective hiring send signals about management's interest in ensuring a large pool of highly competent employees, whereas enhanced training sends a message about management's intention to reinforce employees' competencies (Gong et al., 2009). Motivation-enhancing practices provide the needed inducements that help direct employees' efforts towards valuable goals, whereas opportunity-enhancing practices empower employees to apply their creative knowledge at work (Subramony, 2009). Employees interpret these signals as an indication that management values them and has respect for their contribution to organizational success. This in turn stimulates a sense of duty, in which employees feel obliged to reciprocate through greater levels of commitment to the organization (Whitener, 2001).

In addition to improving employees' affective commitment, we expect all three subsets of HRM systems to indirectly influence employees' innovative behaviors. We expect this to be a positive mediation relationship through affective commitment. The rationale for this is that affectively committed employees have a greater desire to contribute meaningfully to the organization and therefore tend to be more creative (Gould-Williams, 2003; Paré \& Tremblay, 2007). Employees' strong affective attachment to the organization also manifests in their willingness to exercise 
discretionary effort towards promoting organizational goals (Gardner et al., 2011). We expect these collective efforts to enhance the innovative capacity of the organization; thus, we predict a model in which all three HRM subdimensions shape employees' sense of organizational attachment and, through this, improve their innovative behaviors.

Hypothesis 3. (a) Skill-, (b) motivation-, and (c) opportunityenhancing HRM practices indirectly improve employees' innovative behaviors by increasing their affective commitment.

Despite the rather optimistic prediction of Hypothesis 3, sceptics of the mutual gains perspective suggest that the benefits of HRM practices are typically achieved through high job demands and increased stress for employees (Godard, 2001; Kroon et al., 2009; Ramsay et al., 2000). Specific sets of HRM practices that have positive effects on employee performance and well-being may not necessarily have favorable effects in terms of employees' experience of stress (Van de Voorde et al., 2012). In fact, higher levels of performance may be driven, in part, by increased job demands and a level of stress-inducing pressure to perform. Thus, unlike the mutual gains perspective, we do not expect all three subdimensions of the HRM system to have similar patterns of positive effects when linked to outcomes such as work-related stress. Rather, we expect differential effects across the various components of the HRM system.

For skill-enhancing practices, we expect a negative association with employees' reports of high job demands. We make this argument on the basis that employees who are well suited for their positions are less likely to perceive their jobs as being too demanding or intense. Skill-enhancing HRM practices ensure employees have the skills needed for task performance (Jiang et al., 2012), and this places them in a much better position to cope with high job demands. Similarly, motivation-enhancing HRM practices represent job resources that help in tackling high job demands. Research has shown that the levels of support offered to employees, either directly through assistance with difficult tasks (Bakker \& Demerouti, 2007) or indirectly through well-designed performance management practices (Ogbonnaya et al., 2017), allow employees to thrive in challenging jobs. These job resources activate a motivation-driven process allowing employees to manage specific work stress factors that require sustained physical, cognitive, and emotional effort (Bakker \& Demerouti, 2007). 
It would seem therefore that lower reports of job demands due to skill- and motivation-enhancing HRM practices may contribute to a reduction in employees' experience of stress. As a considerable amount of evidence has established high job demands to be an important antecedent of stress (Bakker \& Demerouti, 2007; Green, 2001; Kroon et al., 2009; Ogbonnaya et al., 2017), any reduction in job demands will likely make employees less susceptible to stressful work conditions. Drawing on these studies, we argue that the same would apply if skill- and motivation-enhancing practices reduce employees' perceptions of job demands. In other words, employees will be less likely to report higher stress levels.

Hypothesis 4. (a) Skill- and (b) motivation-enhancing HRM practices indirectly reduce employees' experience of stress through lower levels of job demands.

Opportunity-enhancing practices provide a more nuanced perspective with regard to employee well-being and stress. On the one hand, providing opportunities for employees to engage more fully with their work might positively affect their sense of self-determination and autonomous motivation (Gagné \& Deci, 2005). In fact, both team working and job autonomy are likely to service key nutriments of self-determination in relatedness and autonomy while also providing employees with greater meaning and engagement in their work roles (Ryan \& Deci, 2000). At the same time, however, providing teamwork and increasing job autonomy may create a more challenging task environment that enhances job demands and increases levels of stress. For example, research evidence demonstrates that team working can intensify work due to an increased potential for both task and relationship conflicts, the increased likelihood of peer surveillance, concertive control, and the need to juggle one's team role alongside other individual work responsibilities (Barker, 1993; Godard, 2001; Macky \& Boxall, 2008). Similarly, the level of job autonomy experienced by many employees may not effectively mitigate the pace and intensity of their work depending upon the workloads imposed on them by management (Harley, 1999; Kalmi \& Kauhanen, 2008). If these arguments apply, then we would expect opportunity-enhancing HRM practices to actually increase perceptions of job demands.

In addition to increasing perceptions of high job demands, opportunity-enhancing HRM practices may also increase the experience of stress 
among employees. This assumption holds true given considerable support for a positive relationship between high job demands and excessive pressures at work (Kroon et al., 2009; Macky \& Boxall, 2008). The opportunities for direct employee involvement in discretionary activities may promote employees' sense of empowerment, but often at the expense of work intensification, and correspondingly, high stress levels (Ramsay et al., 2000). Thus, if opportunity-enhancing HRM practices intensify work, it seems reasonable to posit that high job demands will in turn increase employees' experience of stressful work.

Hypothesis 5. Opportunity-enhancing HRM practices will indirectly increase employees' experience of stress by increasing job demands.

\section{Methodology}

\subsection{Sample}

We used data from the employee component of the Finnish 2012 Practices of Working Life Survey (PWLS). The PWLS provides matched employer-employee data on employment practices, working conditions, and employees' experiences of these. The survey was influenced by a European project known as Measuring the Dynamics of Organizations and Work (MEADOW). The MEADOW project gathers harmonized data on the economic and social impact of workplace practices to encourage comparative research on organizational change across Europe. The sample of workplaces for the employer component of the PWLS was drawn from Statistics Finland's Business Register of all enterprises, corporations, and establishments in Finland. Before data collection, a senior person (e.g., the proprietor, top executive, or workplace manager) at workplaces on this register was contacted and invited to take part in the survey. A total of 1,561 responses (i.e., one response for each workplace) were received with a response rate of $76.1 \%$. These workplaces are classified by Statistics Finland as private (66\%) and public (33\%) sector organizations employing at least 10 people. Over $61 \%$ of workplaces are domestic or Finnish-owned organizations, 9\% are foreign-owned organizations, and $21 \%$ are government-owned organizations. 
Given our focus on employees' perceptions of and reactions to HRM practices, we used data from the employee component of the PWLS, involving self-completion questionnaires distributed to a random selection of employees at workplaces where employer data were collected. About 1,711 questionnaires were completed and returned with a response rate of $48.5 \%$. The sample comprises one employee respondent from 1,079 smaller workplaces and two employee respondents from 316 larger workplaces (i.e., a total of 632 employees from larger workplaces). Around 58\% of respondents were aged between 20 and 49 years, and about $42 \%$ were aged 50 years and above. Forty-nine per cent were female, and $48 \%$ had upper secondary education.

\subsection{Measures}

\subsubsection{HRM practices}

Six HRM practices were identified by following established measures of the AMO framework (Appelbaum et al., 2000; Jiang et al., 2012; Macky \& Boxall, 2007; Subramony, 2009). Our aim was to derive at least two practices for each HRM subdimension: Skill-enhancing HRM practices comprised selective hiring and training; motivation-enhancing HRM practices comprised performance appraisal and workplace support; and opportunity-enhancing HRM practices comprised team working and job autonomy. All six HRM practices were measured by multiple observed items coded such that high values reflected high scores on the construct. See full details of all HRM practices and descriptive statistics in Table 1.

Table 1 also shows the measurement items, response scales, and descriptive statistics for all employee outcomes. Affective commitment was measured by two items based on Allen and Meyer's (1990) affective commitment scale. Job demands was measured by three items consistent with existing measures of time demands (e.g., Boxall \& Macky, 2014). Employees' innovative behaviors was measured by three items from existing measures of innovative work behaviors (De Jong \& Den Hartog, 2010; Ma Prieto \& Pilar Perez-Santana, 2014). Stress was measured by a single item on the extent to which respondents felt tense, restless, nervous, or anxious or had trouble sleeping due to a troubled mind (singleitem measures of stress are believed to perform as effectively as multiitem formulations - see Boxall \& Macky, 2014; Macky \& Boxall, 2008; Stanton, Balzer, Smith, Parra, \& Ironson, 2001). 
Table 1 Study variables, measurement items, factor loadings, and response scale

\begin{tabular}{|c|c|c|c|}
\hline Variables & Items & $\begin{array}{l}\text { Factor } \\
\text { loadings }\end{array}$ & $\begin{array}{l}\text { Response } \\
\text { scales }\end{array}$ \\
\hline \multicolumn{4}{|c|}{ Skill-enhancing HRM practices } \\
\hline \multirow[t]{2}{*}{ Selective hiring } & $\begin{array}{l}\text { Someone hired to do your job would be required to have related } \\
\text { work experience }\end{array}$ & 0.80 & $\begin{array}{l}0=\text { no and } \\
1=y e s\end{array}$ \\
\hline & $\begin{array}{l}\text { How much related work experience would someone hired to do } \\
\text { your job be required to have? }\end{array}$ & 0.98 & $\begin{array}{l}1=\text { less than } 6 \\
\text { months to } 5=5 \\
\text { years or more }\end{array}$ \\
\hline \multirow[t]{4}{*}{ Training } & You participated in training during working hours & 0.59 & $0=$ no and $1=y e s$ \\
\hline & You received written/verbal instructions while performing your normal job & 0.42 & \\
\hline & You studied independently by reading work-related material & 0.57 & \\
\hline & You received some other work-related training & 0.53 & \\
\hline \multicolumn{4}{|c|}{ Motivation-enhancing HRM practices } \\
\hline \multirow[t]{4}{*}{ Performance } & Your performance appraisal directly affected your level of pay appraisal & 0.41 & $0=$ no and $1=y e s$ \\
\hline & Your performance appraisal directly affected your promotion prospects & 0.57 & \\
\hline & Your performance appraisal directly affected your training opportunities & 0.61 & \\
\hline & Your performance appraisal directly affected the content of your work tasks & 0.59 & \\
\hline \multirow[t]{2}{*}{$\begin{array}{l}\text { Workplace } \\
\text { support }\end{array}$} & $\begin{array}{l}\text { You receive assistance from your supervisor/manager if your work } \\
\text { seems difficult }\end{array}$ & 0.69 & $\begin{array}{l}1=\text { never to } \\
3=\text { always }\end{array}$ \\
\hline & You receive assistance from other co-workers if your work seems difficult & 0.40 & \\
\hline \multicolumn{4}{|c|}{ Opportunity-enhancing HRM practices } \\
\hline \multirow[t]{3}{*}{ Team working } & Team members can influence the work targets for the group & 0.79 & $0=$ no and $1=y e s$ \\
\hline & Team members can influence the ways in which these targets are reached & 0.93 & \\
\hline & Team discusses how well the targets have been reached & 0.90 & \\
\hline \multirow[t]{4}{*}{ Job autonomy } & You can influence the range of tasks you do in your job & 0.69 & $1=$ not at all to \\
\hline & You can influence the speed at which you work & 0.40 & $4=$ to a great extent \\
\hline & You can influence the order in which you undertake your tasks & 0.47 & \\
\hline & You can influence how work is allocated between people in your workplace & 0.57 & \\
\hline \multirow{5}{*}{$\begin{array}{l}\text { Affective } \\
\text { commitment } \\
\text { Job demands }\end{array}$} & I am proud to tell people who I work for & 0.67 & 1 = strongly disagree \\
\hline & I can recommend this workplace to my friends as well & 0.82 & to 4 = strongly agree \\
\hline & How often do you work at home doing tasks related to your main job? & 0.71 & $1=$ never to \\
\hline & How often do you do work-related tasks outside of your usual working hours? & 0.91 & $4=$ always \\
\hline & $\begin{array}{l}\text { How often are you contacted by phone or in person on work-related } \\
\text { matters outside your usual working hours? }\end{array}$ & 0.74 & \\
\hline \multirow{3}{*}{$\begin{array}{l}\text { Employees' } \\
\text { innovative } \\
\text { behaviors }\end{array}$} & $\begin{array}{l}\text { Over the past } 12 \text { months, have you figured out solutions for improving } \\
\text { areas of your own work? }\end{array}$ & 0.63 & $0=$ no and $1=y e s$ \\
\hline & $\begin{array}{l}\text { Over the past } 12 \text { months, have you thought up new or improved products } \\
\text { or services for your employer? }\end{array}$ & 0.53 & \\
\hline & $\begin{array}{l}\text { Over the past } 12 \text { months, have you tried to persuade your supervisor } \\
\text { or manager to support new ideas? }\end{array}$ & 0.58 & \\
\hline Stress & $\begin{array}{l}\text { To what extent are you currently feeling tense, restless, nervous, or anxious } \\
\text { or having trouble sleeping because your mind is troubled? }\end{array}$ & 0.84 & $\begin{array}{l}1=\text { not at all to } 5= \\
\text { to a great extent }\end{array}$ \\
\hline
\end{tabular}

Sample size $=1,711$. HRM: human resource management. 


\subsubsection{Control variables}

We controlled for a number of variables, which were recoded as dummies: contract type ("temporary" or "permanent"), employment status ("full-time" or "part-time"), working hours (three categories: "irregular working hours" or "regular working hours without flexibility," reference is "regular working hours with flexibility"); sex ("male" or "female”), age (five bands: "20-29 years," "30-39 years," "40-49 years," or "60 years and above," reference is "50-59 years"), education (four categories: "lower secondary education," "lower degree tertiary," or "higher tertiary," reference is "upper secondary education"), tenure (five categories: "less than one year," "one to less than two years," "two to less than five years," or "five to less than ten years," reference is "10 years and over"). Our set of control variables is consistent with previous research (e.g., Macky \& Boxall, 2007; Ramsay et al., 2000).

\section{Data analysis}

Data were analyzed by structural equation modelling (SEM) with latent variables, performed using the Mplus software program (Version 7.11). Our models were estimated by the robust maximum likelihood estimator that adjusts for errors in measures and accounts for nonnormality in data (Asparouhov \& Muthén, 2006). The robust maximum likelihood estimator also accommodates continuous and categorical data simultaneously (Muthén \& Muthén, 2010) and thus is well suited for the varying response formats of our measurement items.

We began our analysis by estimating measurement models to ensure all observed items were appropriate indicators of presumed latent constructs. The first measurement model comprised four sets of equations: (a) latent constructs for the six HRM practices, (b) a second-order latent construct of all six HRM practices, (c) latent constructs for affective commitment and job demands, and (d) latent constructs for employees' innovative behaviors and stress. The latent construct for stress, a single-item scale, was estimated by Hayduk's (1987) recommended procedure, which specifies a fixed nonzero measurement error variance for the indicator of the single-item latent construct. Overall goodness-offit for the measurement model was adequate $\left(\chi^{2}=1,302.199 ; d f=334\right.$; $p<0.001$; comparative fit index $[\mathrm{CFI}]=0.93$; Tucker-Lewis index [TLI] 
$=0.92$; root mean square error of approximation [RMSEA] = 0.04; standardized root mean

square residual $[\mathrm{SRMR}]=0.05)$. All free factor loadings were significant and in the hypothesized direction. The second measurement model was as the first, but instead of a single second-order latent construct of all HRM practices, we estimated three second-order latent constructsone for each HRM subdimension. This model established that our three HRM subdimensions were discrete $(\chi 2=1,105.398 ; d f=323 ; p<0.001$; $\mathrm{CFI}=0.94 ; \mathrm{TLI}=0.93 ; \mathrm{RMSEA}=0.04 ; \mathrm{SRMR}=0.05$ ).

To minimize concerns of common-method variance, a one-factor measurement model of all study variables was estimated. This model failed to fit the data $(\chi 2=9,204.557 ; d f=350 ; p<0.001 ; \mathrm{CFI}=0.31 ; \mathrm{TLI}=0.25$; RMSEA = 0.12; SRMR = 0.12). A two-factor measurement model, involving all HRM practices as one latent construct and other variables as the second latent construct, also failed to fit the data $(\chi 2=8,862.684 ; d f=$ 349; $p<0.001 ; \mathrm{CFI}=0.34 ; \mathrm{TLI}=0.28 ; \mathrm{RMSEA}=0.12 ; \mathrm{SRMR}=0.13$ ).

Hypotheses 1 and 2 were examined by adding two sets of structural equations to our first measurement model; thus, (a) employees' innovative behaviors and stress were regressed on the second-order factor of all six HRM practices (hereafter "perceived HRM system"), affective commitment and job demands, respectively; and (b) affective commitment and job demands were regressed on the perceived HRM system. Following standard SEM principles, all control variables were embedded within the covariance matrix of the model.

To examine Hypotheses 3 to 5, we estimated three separate structural models for each HRM subdimension. For example, the relationships involving skill-enhancing HRM practices were estimated separately from motivation- and opportunity-enhancing HRM practices. Separate models were estimated to isolate the effects of each HRM subdimension and ensure they do not suppress one another. For each model, we estimated two sets of structural equations in addition to the relevant measurement component; thus, (a) employees' innovative behavior and stress were regressed on the HRM subdimension, affective commitment and job demands, respectively; and (b) affective commitment and job demands were regressed on the HRM subdimension. Control variables were also embedded within the covariance matrix of each model.

The indirect relationships via affective commitment and job demands were estimated on the basis of the product- of-coefficient $(\alpha \beta)$ approach 
(MacKinnon, Lockwood, Hoffman, West, \& Sheets, 2002). This approach estimates the product of $\alpha$, the regression coefficient between the predictor and mediator, and $\beta$, the regression coefficient between the mediator and outcome. Statistical significance for indirect relationships was validated by bias-corrected bootstrapping (MacKinnon et al., 2002).

\section{Results}

Bivariate correlations among study variables are presented in Table 2. All correlations are consistent with our expectations; the exceptions are perceived HRM system and skill-enhancing HRM practices are not significantly correlated with affective commitment and skill-enhancing HRM practices are positively correlated with stress. Results of multivariate relationships are provided in Figures 1-4. The figures show standardized regression coefficients and residuals for all direct and indirect paths in our models. The figures also show bias-corrected bootstrap confidence intervals for all indirect relationships via affective commitment and job demands to employees' innovative behaviors and stress, respectively.

As shown in Figure 1, the perceived HRM system was directly and positively related with affective commitment $(\beta=0.21, p<0.001)$, job demands $(\beta=0.22, p<0.001)$, and employees' innovative behaviors $(\beta=0.23, p<0.001)$. No significant direct relationship was observed for stress. The indirect path from the perceived HRM system via affective commitment was positive for employees' innovative behaviors

Table 2 Bivariate correlations among study variables

\begin{tabular}{|c|c|c|c|c|c|c|c|}
\hline Variables & 1 & 2 & 3 & 4 & 5 & 6 & 7 \\
\hline 1 Affective commitment & 1 & & & & & & \\
\hline 2 Job demands & $0.09 * * *$ & & & & & & \\
\hline 3 Employees' innovative behavior & $0.12^{* * *}$ & $0.58^{* * *}$ & & & & & \\
\hline 4 Stress & $-0.40^{* * *}$ & $0.41^{* * *}$ & $0.27^{* * *}$ & & & & \\
\hline 5 Perceived HRM system & 0.04 & $0.29 * * *$ & $0.31^{* * *}$ & $0.14^{* * *}$ & & & \\
\hline 6 Skill-enhancing HRM practices & 0.04 & $0.29 * * *$ & $0.31^{* * *}$ & $0.14^{* * *}$ & $0.33^{* * *}$ & & \\
\hline 7 Motivation-enhancing HRM practices & $0.45^{* * *}$ & $0.17^{* * *}$ & $0.52^{* * *}$ & $-0.08^{* * *}$ & $0.12^{* * *}$ & $0.12^{* * *}$ & \\
\hline 8 Opportunity-enhancing HRM practices & $0.21^{* * *}$ & $0.25^{* * *}$ & $0.34^{* * *}$ & $0.08^{* *}$ & $0.148^{* * *}$ & * $0.14 * * *$ & $0.30^{* * *}$ \\
\hline
\end{tabular}

Sample size $=1,711$. HRM: human resource management.

*** $p<0.001 ;{ }^{* *} p<0.01$; $^{*} p<0.05$ 


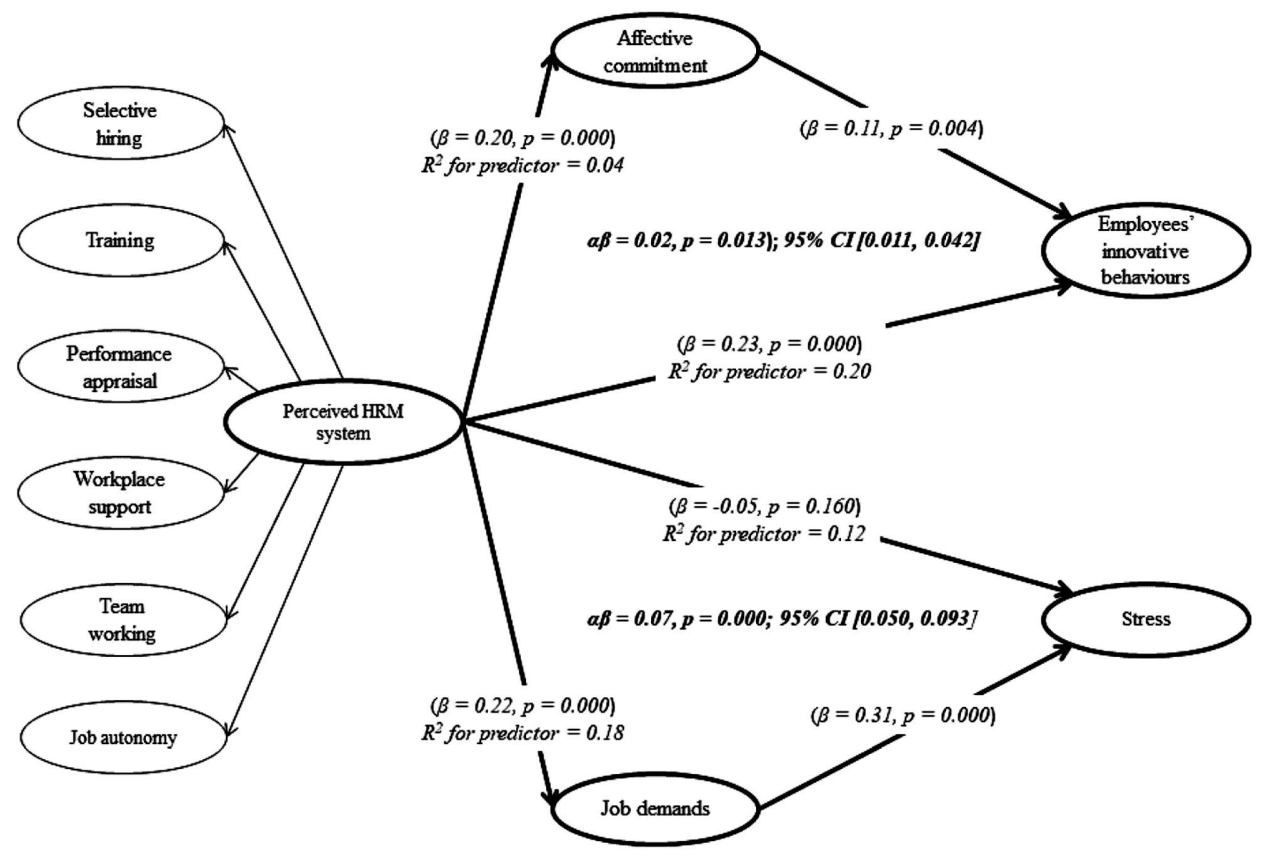

Figure 1 Structural equation modelling mediation model involving perceived human resource management (HRM) system

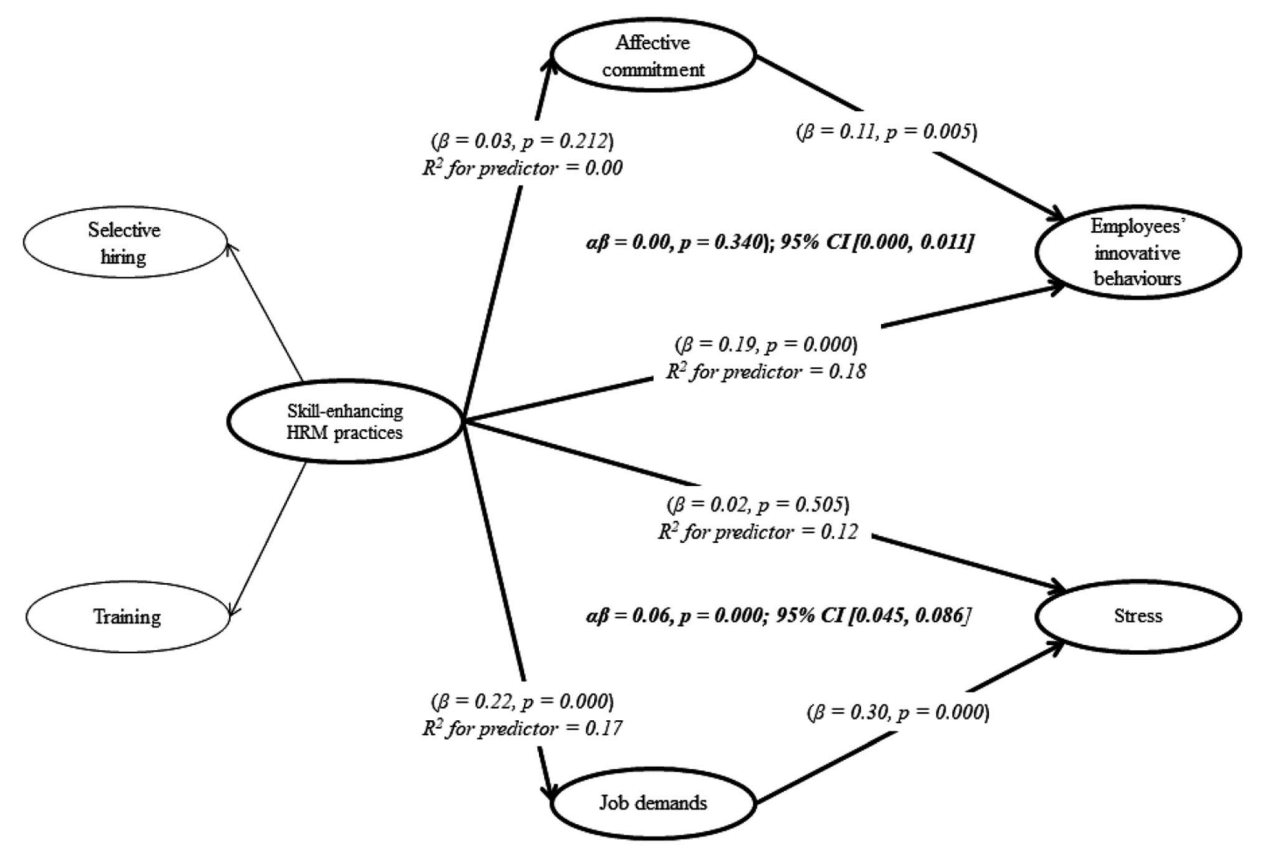

Figure 2 Structural equation modelling mediation model involving skill-enhancing human resource management (HRM) practices 


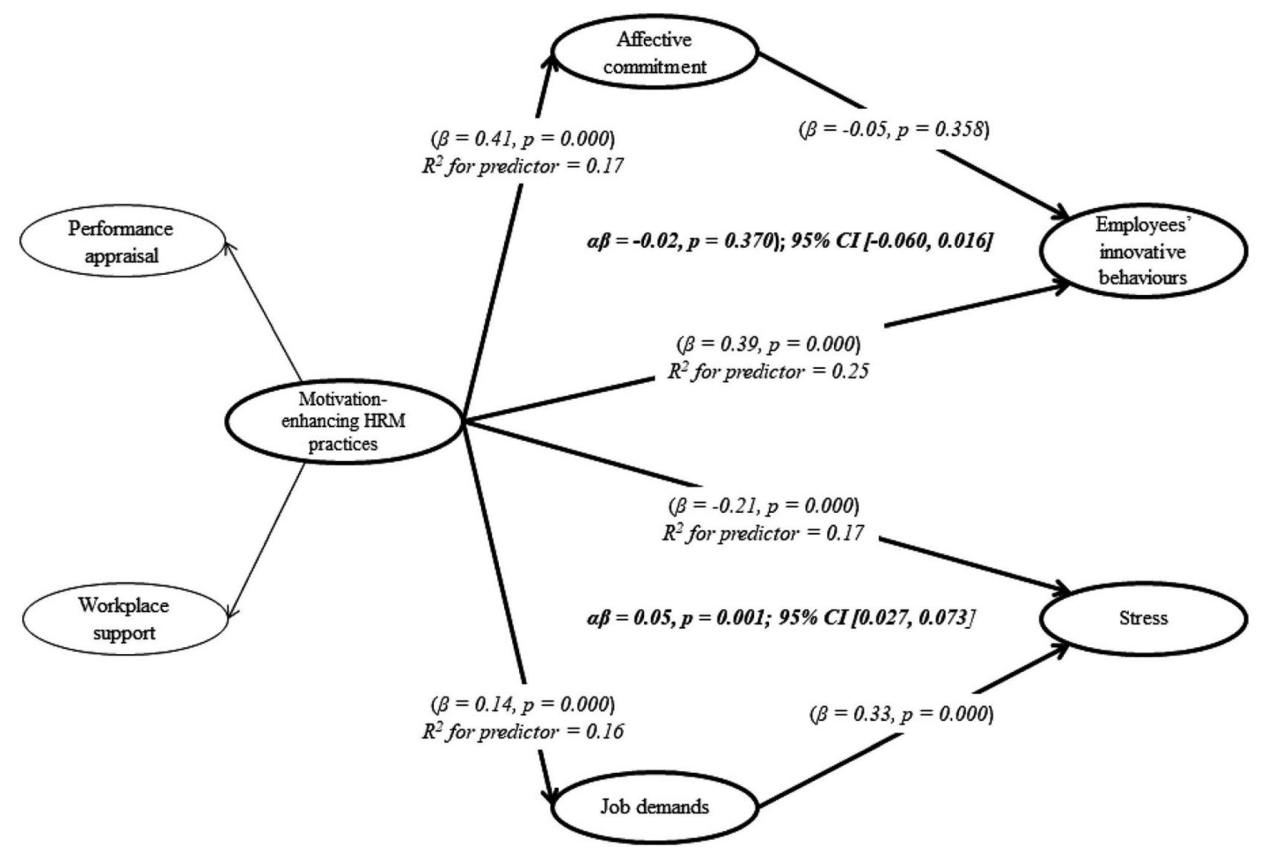

Figure 3 Structural equation modelling mediation model motivation-enhancing human resource management (HRM) practices

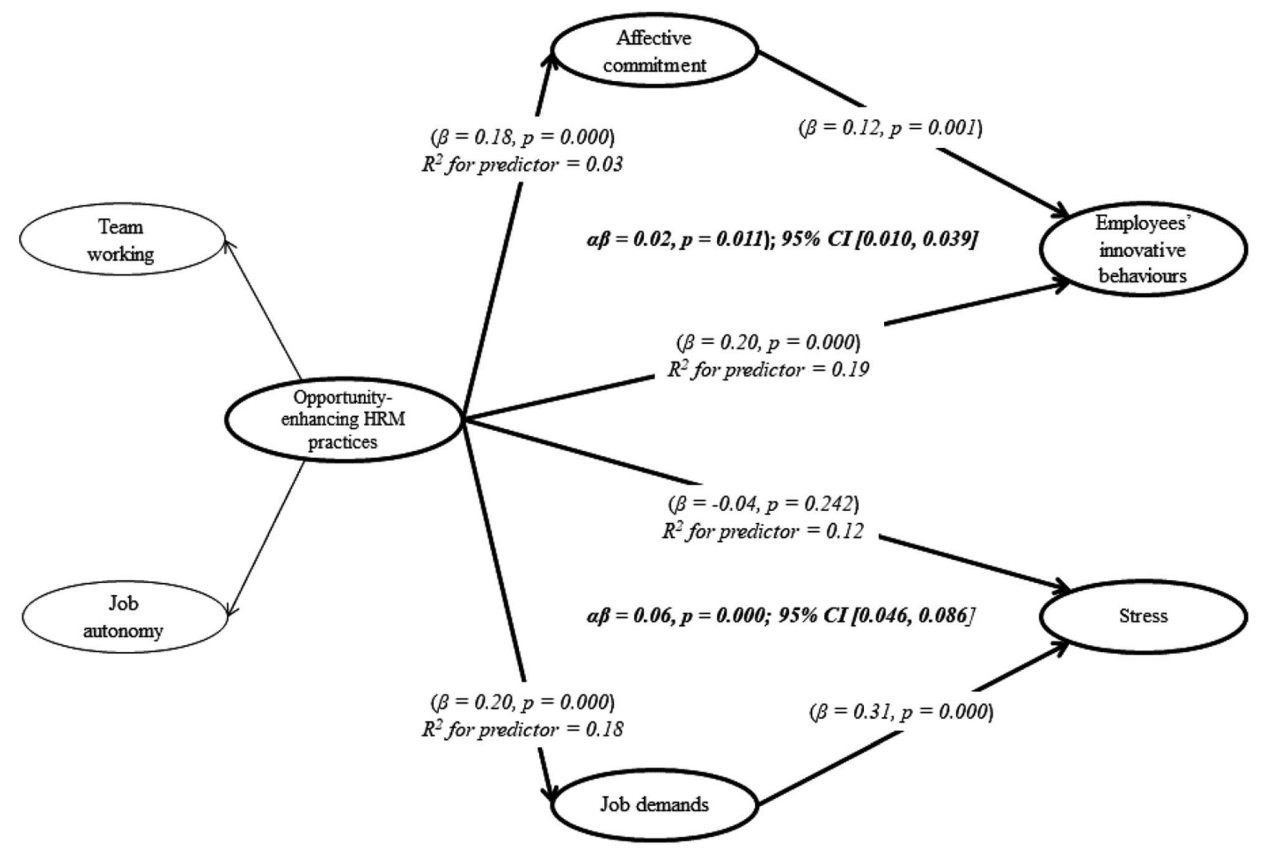

Figure 4 Structural equation modelling mediation model involving opportunityenhancing human resource management (HRM) practices 
$(\alpha \beta=0.02, p<0.05)$, thus providing full support for the mutual gains prediction of Hypothesis 1. With regard to the conflicting outcomes perspective, Hypothesis 2 was also fully supported as the indirect path from the perceived HRM system to stress via job demands was positive ( $\alpha \beta$ $=0.07, p<0.001$ ).

Skill-enhancing HRM practices were directly and positively related with job demands $(\beta=0.22, p<0.001)$ and employees' innovative behaviors $(\beta=0.19, p<0.001)$. However, their direct relationships with affective commitment and stress were not significant. Given a nonsignificant direct path between skill-enhancing HRM practices and affective commitment, the indirect path to employees' innovative behaviors was correspondingly not significant. Thus, skill-enhancing HRM practices showed no support for the mutual gains prediction of Hypothesis $3(a)$. In contrast, the indirect path from skill-enhancing HRM practices to stress via job demands was significant and positive $(\alpha \beta=0.06, p<$ $0.001)$. Although this result is consistent with the conflicting outcomes perspective, it contradicts our prediction for Hypothesis 4(a) as we expected skill-enhancing HRM practices to reduce employees' stress levels through a reduction in perceived job demands.

Unlike the skill-enhancing subdimension, motivation-enhancing HRM practices were positively associated with affective commitment $(\beta=0.41, p<0.001)$ and employees' innovative behaviors $(\beta=0.39, p$ $<0.001$ ). The direct effects of motivation-enhancing HRM practices on job demands and stress were positive $(\beta=0.14, p<0.001)$ and negative $(\beta=-0.21, p<0.001)$, respectively. Interestingly, no significant indirect paths via affective commitment were observed between motivation-enhancing HRM practices and employees' innovative behaviors. Thus, there was no support for Hypothesis 3(b). Instead, we found evidence for a positive indirect path between motivation-enhancing HRM practices and stress via job demands $(\alpha \beta=0.05, p<0.01)$. This result is consistent with the conflicting outcomes perspective, but contradictory to our prediction for Hypothesis 4(b).

Of the three HRM subdimensions, only opportunity-enhancing HRM practices showed similar effects as the full HRM system. Opportunityenhancing HRM practices were directly and positively associated with affective commitment $(\beta=0.18, p<0.001)$, job demands $(\beta=0.20, p<$ 0.001 ), and employees' innovative behaviors ( $\beta=0.20, p<0.001)$, but not significantly associated with stress. The indirect relationship via 
affective commitment to employees' innovative behaviors was positive $(\alpha \beta=0.02, p<0.05)$, thus providing full support for the mutual gains prediction of Hypothesis 3(c). Furthermore, the indirect path from opportunity-enhancing HRM practices to stress via job demands was significant and positive $(\alpha \beta=0.06, p<0.001)$, fully supporting Hypothesis 5 .

\subsection{Post hoc analysis}

The intent of this study was to develop a more nuanced understanding of disparate components of the HRM system and their unique effects on outcomes. As such, we originally tested Hypotheses 3-5 by examining three subdimensions of HRM practices separately. However, to be consistent with the broader literature in strategic HRM, we also wanted to simultaneously examine the effects of these subdimensions in a single analysis. The results paint a slightly different picture from our main analysis. For example, the effects of ability-enhancing practices $(\beta=-0.03, p>0.05)$ and opportunity-enhancing practices $(\beta=$ $0.04, p>0.05$ ) were nonsignificant on affective commitment, whereas motivation-enhancing practices revealed a positive effect $(\beta=0.72, p$ $<0.001)$. Ability-enhancing practices $(\beta=-0.05, p>0.05)$ and opportunity-enhancing practices $(\beta=0.08, p>0.05)$ also showed no significant effects on job demands, but the effect of motivation-enhancing practices was again significant $(\beta=0.71, p<0.71)$. These results indicate that motivation-enhancing practices may have the most dominant association with outcomes in this particular study, displaying a propensity to suppress the effects of the other bundles. It may be that much of the variance explained by HRM systems in general is being driven by a relatively small number of motivation-enhancing practices, rather than the full system. Our findings therefore highlight the need for more contingency-driven models to better understand the attitudinal and behavioral effects of HRM systems.

\section{Discussion}

The present study explored the role of perceived HRM practices in understanding the trade-offs between employee performance and wellbeing. The study also examined whether three subdimensions of HRM 
practices have differential relationships with employee outcomes. Our predictions were underpinned by two theoretical viewpoints. In line with the mutual gains perspective, we found evidence that the perceived HRM system (i.e., all six HRM practices combined) was positively associated with employees' affective commitment, which in turn was associated with improved innovative behaviors among employees. This finding corroborates previous studies linking HRM practices to positive employees' attitudes directed towards organizational performance (e.g., Gould-Williams, 2003; Macky \& Boxall, 2007; Takeuchi et al., 2009). HRM practices are workplace structures that communicate clear signals about what the organization expects from employees. Employees receive these signals as favorable treatment from the organization and reciprocate through positive workplace attitudes and behaviors.

Although research on the mutual gains paradigm has focused on entire systems of HRM practices, less is known about subsystems of HRM practices. Our analysis sought to extend the mutual gains argument by examining whether three subdimensions of HRM practices improve employees' affective commitment and, in turn, their innovative behaviors. Of the three subdimensions, only opportunity-enhancing HRM practices showed full support for the mutual gains hypothesis. Opportunity-enhancing HRM practices, including team working and job autonomy, were positively related to affective commitment, and correspondingly, to employees' innovative behaviors. The present study is arguably the first to identify opportunity-enhancing practices as key drivers of both employees' commitment and innovativeness at work. When employees have the opportunity to directly influence the nature of their job, they are able to work flexibly and take greater responsibility for the quality of work done (Jiang et al., 2012), leading to workplace effectiveness. Along these lines, opportunity-enhancing practices represent an important HRM function likely to generate performance gains for the workplace.

In contrast, ability- and motivation-enhancing HRM practices showed partial support for the mutual gains argument. Although ability-enhancing practices had a direct positive relationship with employees' innovative behaviors, they were neither directly associated with affective commitment nor indirectly associated with employees' innovative behaviors through affective commitment. For motivation-enhancing HRM practices, our analysis revealed a positive direct relationship with affective commitment, but no significant indirect relationship with employees' 
innovative behaviors. These results indicate that efforts aimed at improving employees' skill and motivation may not necessarily translate into performance improvements for the organization, at least when compared with efforts aimed at improving employees' opportunities to directly influence their job.

Turning now to the conflicting outcomes perspective, we found evidence that perceptions of the HRM system were associated with increased job demands, which also contributed to higher levels of stress among employees. Thus, in addition to improving employees' affective commitment and innovative behaviors, an interrelated set of HRM practices may also intensify work at the expense of employee well-being. This finding is consistent with prior employee involvement research (e.g., Ogbonnaya \& Valizade, 2015; Ramsay et al., 2000) where HRM practices were shown to have unfavorable consequences for employee well-being. HRM systems are designed to delegate decision-making authority and responsibility to employees (Subramony, 2009) and can therefore stimulate employees to expend greater work effort. At the same time, employees who experience higher job demands and intensity due to HRM practices are more likely to report stressful patterns of work (Kroon et al., 2009; Ramsay et al., 2000).

Furthermore, all three subdimensions of HRM practices showed support for the conflicting outcomes perspective. Thus, whether or not HRM practices focus on workers' skills development, workers' motivation to perform well, or opportunities for discretionary effort, there is potential for employees to report increased job demands and, consequently, more stressful work. Although we did not expect skill- and motivationenhancing HRM practices to align with the conflicting outcomes paradigm, our results reflect the possibility that such practices are associated with high performance expectations imposed on employees. Employers who invest in staff training, performance appraisals, or other skill-enhancement initiatives tend to have an expectation to generate returns on their investments. The employers' intent might be to generate investment gains, but their actions may inadvertently induce high job demands among employees. Of course, it bears noting that stressful work need not always carry a negative connotation. Many of the more coveted roles in organizations are likely to be stress filled but also provide incumbents with a deep sense of meaningfulness. Therefore, it is certainly plausible that many employees simultaneously experience both affective commitment and a heightened sense of job demands. 
Our study has theoretical implications for HRM research. First, we add to the much debated question of whether the set of HRM practices directed towards improving organizational performance is necessarily the same set of practices that promote employee well-being (Van De Voorde et al., 2012). We also illuminate critical questions about the extent to which certain HRM practices might be perceived as being exploitative given their negative influence on employee well-being (Ogbonnaya et al., 2017). In particular, opportunity-enhancing practices have emerged from our analysis as the HRM dimension with the most complex pattern of impact on employee performance and wellbeing outcomes. As much as opportunity-enhancing HRM practices might be worth pursuing due to productivity gains, their adoption may also lead to high job demands and stress. At the same time, demanding work may very well be meaningful, interesting, and valuable work for employees. This finding suggests a potential curvilinear relationship between work demands and employee outcomes that needs to be further investigated in the research literature. Further, this observation may point to a need for additional research on the ways in which such practices are implemented and communicated to employees.

Second, our study supports the theory that separate HRM dimensions have differential relationships with both employee performance and well-being. Depending on their respective compositions, subsystems of HRM practices may have positive, negative, or nonsignificant associations with employees' well-being and capacity to perform well. These differential effects tend to have been underestimated in studies where HRM practices were examined as entire systems of practices. Moreover, the range of positive, negative, and nonsignificant effects of the three HRM subdimensions indicates that the mutual gains and conflicting outcomes perspectives may not be mutually exclusive. Job demands and employee well-being are not necessarily opposite poles. Providing employees with greater responsibility and autonomy will likely make their work roles more engaging but will also carry a side effect of enhanced demands and stress. Insofar as HRM systems can be oriented towards multiple goals (cost-effectiveness vs. human capital development) and managers face decisions regarding what goals are most relevant, researchers may be wise to move away from an emphasis on only the positive outcomes of HRM practices and instead embrace a more balanced view.

Furthermore, increases in job demands may not always signify that employees are being exploited, as is often the view in the critical school 
of thought. The truth likely lies with both positions. Employers do implement HRM systems with the goal of improving productivity and performance; however, employees may also gain from having more responsibility and opportunity. This is supported by our findings linking the HRM practice bundles to affective commitment. At the same time, firms must also be wary of inducing job demands and stress levels that become counterproductive for both parties. Clearly, more research is required to determine the nature of possible trade-offs between positive and adverse outcomes of HRM practices and the ways of achieving balance within this complicated system. Future studies may, for example, examine the mediating roles of both happiness-related (e.g., job satisfaction) and health-related (e.g., exhaustion) measures of well-being, to shed new light on different mediating pathways in the HRM/well-being/ performance nexus. In sum, the results of this study suggest that the answer to the question of HRM systems' effect on employee well-being is not dichotomous. HRM systems likely interact with other critical internal system factors and individual dispositions to produce outcomes for individual employees. Greater attention, therefore, needs to be given to the nuances within the relationship.

The present study is not without limitations. First, the use of a singleitem measure of stress represents a methodological weakness as such measures may be less statistically robust compared with multiple-item scales. We address this limitation by following standard procedures for SEM analysis (e.g., Hayduk, 1987). Second, the cross-sectional design of our study presents the possibility of common-method bias, despite the relatively robust and comprehensive analytical procedure employed. Our cross-sectional design has also precluded us from establishing any causality in relation to the effects of the three HRM dimensions. Although a longitudinal design is desirable for empirical analysis of workplace performance outcomes, our predictions were grounded in theory that allowed useful comparison with the existing evidence base.

Notwithstanding these limitations, the present study has practical implications for employers and HRM researchers. Whereas some employers (perhaps due to limited resources) might be unable to simultaneously adopt an extensive range of HRM practices, they may concentrate on particular subsets of practices that address specific goals. For example, if the intention is to build a set of affectively committed employees, employers may prioritize practices that motivate workers to 
exercise discretionary effort and make positive contributions towards workplace innovativeness. Clearly, the data tested in our study cannot provide definitive answers to inquiries about best HRM practices, but future research may choose to delve more deeply into the differential effects of HRM subbundles. In doing so, researchers should recognize that HRM practices that bring about positive organizational effects may not inevitably promote employee well-being. Some HRM practices stimulate perceptions that work is more intense, and the organizational gains of such practices may come at the expense of employee well-being. At the same time, employers must adopt a realistic view of HRM systems and be mindful of both the ways in which the practices are implemented and the messages that are communicated to employees. Carefully "checking the temperature" of employees will be important to realizing optimal gains from HRM system enhancements.

Acknowledgments The authors would like to thank the Finnish Social Science Data Archive for access to the employer and employee data for the Finnish 2012 Practices of Working Life Survey. Data were collected by Statistics Finland's Interview and Survey Services, managed by the University of Tampere, Work Research Center. None of these organizations bear any responsibility for the authors' analysis and interpretations of the data.

Conflicts of interest The authors declare that they have no conflicting interests.

\section{References}

Alfes, K., Shantz, A., \& Truss, C. (2012). The link between perceived HRM practices, performance and well-being: The moderating effect of trust in the employer. Human Resource Management Journal, 22, 409-427.

Alfes, K., Shantz, A. D., Truss, C., \& Soane, E. C. (2013). The link between perceived human resource management practices, engagement and employee behavior: A moderated mediation model. International Journal of Human Resource Management, 24, 330-351.

Allen, N., \& Meyer, J. (1990). The measurement and antecedents of affective, continuance, and normative commitment to the organization. Journal of Occupational Psychology, 63, 1-18.

Appelbaum, E., Bailey, T., Berg, P., \& Kalleberg, A. (2000). Manufacturing advantage: Why high-performance work systems pay off. Ithaca, NY: ILR Press.

Asparouhov, T., \& Muthén, B. (2006). Multilevel modeling of complex survey data. Paper presented at the American Statistical Association Conference. Seattle, WA: American Statistical Association. 
Bakker, A., \& Demerouti, E. (2007). The job demands-resources model: State of the art. Journal of Managerial Psychology, 22, 309-328.

Barker, J. (1993). Tightening the iron cage: Concertive control in self-managing teams. Administrative Science Quarterly, 38, 408-437.

Boxall, P., Ang, S. H., \& Bartram, T. (2011). Analysing the 'black box' of HRM: Uncovering HR goals, mediators, and outcomes in a standardized service environment. Journal of Management Studies, 48, 1504-1532.

Boxall, P., \& Macky, K. (2014). High-involvement work processes, work intensification and employee well-being. Work, Employment and Society, 28, 963-984.

De Jong, J., \& Den Hartog, D. (2010). Measuring innovative work behavior. Creativity and Innovation Management, 19, 23-36.

Delery, J. (1998). Issues of fit in strategic human resource management: Implications for research. Human Resource Management Review, 8, 289-309.

Gagné, M., \& Deci, E. L. (2005). Self-determination theory and work motivation. Journal of Organizational Behavior, 26, 331-362.

Gardner, T., Wright, P., \& Moynihan, L. (2011). The impact of motivation, empowerment, and skill-enhancing practices on aggregate voluntary turnover: The mediating effect of collective affective commitment. Personal Psychology, 64, 315-350.

Godard, J. (2001). High performance and the transformation of work? The implications of alternative work practices for the experience and outcomes of work. Industrial and Labor Relations Review, 54, 776-805.

Gong, Y., Law, K., Chang, S., \& Xin, K. (2009). Human resources management and firm performance: The differential role of managerial affective and continuance commitment. Journal of Applied Psychology, 94, 263-275.

Gould-Williams, J. (2003). The importance of HR practices and workplace trust in achieving superior performance: A study of public-sector organizations. International Journal of Human Resource Management, 14, 28-54.

Green, F. (2001). It's been a hard day's night: The concentration and intensification of work in late twentieth-century Britain. British Journal of Industrial Relations, $39,53-80$.

Guest, D. (2017). Human resource management and employee well-being: Towards a new analytic framework. Human Resource Management Journal, 27, 22-38.

Harley, W. (1999). The myth of empowerment: Work organization, hierarchy and employee autonomy in contemporary Australian workplaces. Work, Employment and Society, 13, 41-66.

Hayduk, L. (1987). Structural equation modeling with LISREL: Essentials and advances. Baltimore, MD: Johns Hopkins University Press.

Hayton, J. C. (2005). Promoting corporate entrepreneurship through human resource management practices: A review of empirical research. Human Resource Management Review, 15, 21-41.

Jiang, K., Hu, J., Liu, S., \& Lepak, D. P. (2017). Understanding employees' perceptions of human resource practices: Effects of demographic dissimilarity to managers and coworkers. Human Resource Management, 56, 69-91. 
Jiang, K., Lepak, D., \& Baer, J. (2012). How does human resource management influence organizational outcomes? A metaanalytic investigation of mediating mechanisms. Academy of Management Journal, 55, 1264-1294.

Kalmi, P., \& Kauhanen, A. (2008). Workplace innovations and employee outcomes: Evidence from Finland. Industrial Relations: A Journal of Economy and Society, 35, 430-459.

Kroon, B., Van de Voorde, K., \& Van Veldhoven, M. (2009). Cross-level effects of high-performance work practices on burnout: Two counteracting mediating mechanisms compared. Personnel Review, 38, 509-525.

Ma Prieto, I., \& Pilar Perez-Santana, M. (2014). Managing innovative work behavior: The role of human resource practices. Personnel Review, 43, 184-208.

MacKinnon, D., Lockwood, C., Hoffman, J., West, S., \& Sheets, V. (2002). A comparison of methods to test mediation and other intervening variable effects. Psychological Methods, 7, 83-104.

Macky, K., \& Boxall, P. (2007). The relationship between "high performance work practices" and employee attitudes: An investigation of additive and interaction effects. International Journal of Human Resource Management, 18, 537-567.

Macky, K., \& Boxall, P. (2008). High-involvement work processes, work intensification and employee well-being: A study of New Zealand worker experiences. Asia Pacific Journal of Human Resources, 46, 38-55.

Muthén, L., \& Muthén, B. (2010). Mplus user's guide. Los Angeles, CA: Muthén \& Muthén.

Nishii, L., Lepak, D., \& Schneider, B. (2008). Employee attributions of the "why" of HR practices: Their effects on employee attitudes and behaviors, and customer satisfaction. Personnel Psychology, 61, 503-545.

Ogbonnaya, C., Daniels, K., Connolly, S., \& Van Veldhoven, M. (2017). Integrated and isolated impact of high-performance work practices on employee health and well-being: A comparative study. Journal of Occupational Health Psychology, 22, 98-114.

Ogbonnaya, C., \& Valizade, D. (2015). Participatory workplace activities, employeelevel outcomes and the mediating role of work intensification. Management Research Review, 38, 540-588.

Paré, G., \& Tremblay, M. (2007). The influence of high-involvement human resources practices, procedural justice, organizational commitment, and citizenship behaviors on information technology professionals' turnover intentions. Group \& Organization Management, 32, 326-357.

Ramsay, H., Scholarios, D., \& Harley, A. (2000). Employees and high-performance work systems: Testing inside the black box. British Journal of Industrial Relations, 38, 501-531.

Ryan, R. M., \& Deci, E. L. (2000). Intrinsic and extrinsic motivations: Classic definitions and new directions. Contemporary Educational Psychology, 25, 54-67.

Stanton, J., Balzer, K., Smith, P., Parra, L., \& Ironson, G. (2001). A general measure of work stress: The stress in general scale. Educational and Psychological Measurement, 61, 866-888. 
Subramony, M. (2009). A meta-analytic investigation of the relationship between HRM bundles and firm performance. Human Resource Management, 48, 745-768.

Takeuchi, R., Chen, G., \& Lepak, D. (2009). Through the looking glass of a social system: Cross-level effects of high-performance work systems on employees' attitudes. Personnel Psychology, 62, 1-29.

Van De Voorde, K., \& Beijer, S. (2015). The role of employee HR attributions in the relationship between high-performance work systems and employee outcomes. Human Resource Management Journal, 25, 62-78.

Van De Voorde, K., Paauwe, J., \& Van Veldhoven, M. (2012). Employee well-being and the HRM-organizational performance relationship: A review of quantitative studies. International Journal of Management Reviews, 14, 391-407.

Whitener, E. (2001). Do "high commitment" human resource practices affect employee commitment? A cross-level analysis using hierarchical linear modelling. Journal of Management, 27, 515-535. 